\title{
The Night Side of Blood Pressure: Nocturnal Blood Pressure Dipping and Emotional (dys)Regulation
}

\author{
Maria Casagrande ${ }^{1, *(1)}$, Francesca Favieri ${ }^{2}\left(\mathbb{D}\right.$, Viviana Langher ${ }^{1}$, Angela Guarino ${ }^{2}(\mathbb{D}$, \\ Enrico Di Pace ${ }^{2}$, Giuseppe Germanò ${ }^{3}$ and Giuseppe Forte ${ }^{2}$ (i) \\ 1 Dipartimento di Psicologia Dinamica e Clinica, Università di Roma “Sapienza”, 00185 Roma, Italy; \\ viviana.langher@uniroma1.it \\ 2 Dipartimento di Psicologia, Università di Roma "Sapienza", 00185 Roma, Italy; \\ francesca.favieri@uniroma1.it (F.F.); angela.guarino@uniroma1.it (A.G.); enrico.dipace@uniroma1.it (E.D.P.); \\ g.forte@uniroma1.it (G.F.) \\ 3 Dipartimento di Scienze Cardiovascolari, Respiratorie, Nefrologiche e Geriatriche, \\ Università di Roma "Sapienza", 00815 Roma, Italy; ncgerman@tin.it \\ * Correspondence: maria.casagrande@uniroma1.it
}

Received: 3 November 2020; Accepted: 27 November 2020; Published: 30 November 2020

\begin{abstract}
Introduction: The dipping phenomenon is a physiological drop in blood pressure (around 10-20\%) during sleep and represents an event related to the circadian blood pressure trend. This phenomenon, in some cases, is characterized by some alterations that can be expressed by an increase (extreme dipping), a decrease (non-dipping), or a reverse (i.e., higher blood pressure during sleep compared to awake state; reverse-dipping) physiological decline of blood pressure. Few studies focused on the association between the circadian variation of blood pressure and psychological variables, although this information could help understanding how psychological characteristics (e.g., emotional regulation or dysregulation) interact with individuals' physiological processes. Given the association between emotional dysregulation and essential hypertension, this study aimed to investigate the relationship between alexithymia and dipping status in a sample of healthy and hypertensive adults in the absence of other medical conditions. Methods: Two hundred and ten adults took part in the study and were classified, according to ambulatorial blood pressure measure (ABPM), into three groups: dippers $(n=70)$, non-dippers $(n=70)$, and extreme dippers $(n=70)$. The participants completed a socio-demographic and anamnestic interview and the Toronto Alexithymia Scale-20 (TAS-20). Results: The ANOVAs on the TAS-20 subscales showed that the groups differed in the difficulty identifying feelings and difficulty describing feelings. In both the subscales, dippers showed lower scores than non-dippers and extreme dippers. The ANOVA on the global score of TAS-20 confirmed that dippers were less alexithymic than both extreme dippers and non-dippers. Conclusions: This study confirms that some psychological factors, like alexithymia, could represent a characteristic of patients who fail to exhibit an adaptive dipping phenomenon. Moreover, an association between an excessive reduction of BP (extreme dipping) or a lack of the decrease of BP during sleep (non-dipping) and a worse emotional regulation, considering alexithymia construct, was highlighted for the first time, confirming the relevant role of the emotional process in the modulation of an essential psychophysiological process such as the circadian variation of BP.
\end{abstract}

Keywords: blood pressure; dipping status; anger; ambulatory blood pressure monitor

\section{Introduction}

The circadian variation of sympathetic activity during night-time is physiologically accompanied by an increased vagal tone and a marked reduction in heart rate, cardiac output, and total peripheral 
resistance. As a consequence of these autonomic variations, blood pressure (BP) drops during the bed-rest period. Typically, the physiological night-time drop or "dip" of BP ranges between 10 and $20 \%$ compared with daytime BP [1-3]. However, in some cases, this phenomenon may be characterized by an atypical variation.

According to recent hypertension guidelines, assessment of nocturnal BP values and dipping status is enabled by 24-h ambulatory blood pressure monitoring (ABPM), which allows the classification of patients in four different circadian BP phenotypes: (a) dipping: physiological decrease of 10-20\%; (b) non-dipping: reduction of night-time BP less than 10\%; (c) reverse dipping: a rise of night-time BP; and (d) extreme dipping: a night-time BP decrease higher than 20\% [4].

The physiological dipping pattern appears to be a protective factor for cardiovascular health [5]. Conversely, the circadian BP phenotypes of extreme dipping and non-dipping appear to be associated with different risks of organ damage, cardiovascular outcomes, and higher mortality [3,6-8].

It is well known that many psychological factors play an important role in the development and maintenance of altered BP and essential hypertension. The studies focused on hypertension have found an association of hostility, depression, anxiety, coping strategies, and emotional dysregulation with alteration of the normal level of blood pressure [9-14]. However, the causes responsible for nocturnal blood pressure variations remain unclear; some studies have highlighted the possible involvement of some psychological variables, such as anger and hostility [15-17], depression [18], low perceived social support [19], social discrimination [20], and work-related stress [21]. However, to our knowledge, no study analyzed the possible role of emotional dysregulation in dipping alteration.

For the first time, the current study investigates the association between alexithymia, an emotional dysregulation construct, and the BP dipping status. Previous evidence reported higher emotional dysregulation in people with essential hypertension [12,13]. Moreover, both non-dipping and extreme dipping conditions were considered as possible cardiovascular risk factors $[1,8,17,22,23]$. Accordingly, it was expected that both extreme and non-dipping phenotypes would show higher alexithymia scores than dippers.

\section{Method}

\subsection{Participants}

Two hundred and ten participants were recruited at the First Medical Clinic of the Policlinico Umberto I of the University of Rome "Sapienza". A cardiologist provided information about the hypertensive status and dipping conditions. The participants were divided into three groups, according to their bed-time drops of BP: dippers $(n=70)$ who had a dipping ratio between 0.80 and 0.90; non-dippers $(n=70)$ who presented a dipping ratio higher than 0.90 ; and extreme dippers $(n=70)$ who showed a dipping ratio lower than 0.80 .

The inclusion criteria for the study were: (a) age between 40 and 75 years and (b) dipping classification performed by a cardiologist after a 24-h ABPM. The exclusion criteria were a diagnosis of chronic or severe medical and psychiatric pathologies (such as cancer, diabetes, cardiac or neurological pathologies, and psychiatric disorders).

The main characteristics of the samples are shown in Table 1.

\subsection{Assessment Tools}

\subsubsection{Physiological Measures}

Blood pressure office evaluation: systolic (SBP) and diastolic Blood Pressure (DBP) and heart rate were recorded by using an automatic electronic sphygmomanometer (Omron; Kyoto, Japan) validated for self-measurement ("Personal Check" PIC). Blood pressure measurement was performed according to the European guidelines for hypertension [24]. 
Weight status assessment: weight and height, assessed by a balance and a stadiometer, were used to calculate the body mass index (BMI; kg/m²), an indirect estimate of the individual's body fatness.

\subsubsection{Ambulatory Blood Pressure Monitors (ABPM)}

The $24 \mathrm{~h}$ BP was measured with the Takeda ABPM monitor (TM-2430; Takeda Pharmaceutical Company Limited; Tokyo, Japan). The ABPM was set to obtain BP recordings at 15 min intervals during the wake (time range of daily blood pressure: 07:00 to 22:00) and 30 min intervals during sleep (time range of night blood pressure: 22:00 to 07:00) [25]. According to the practice guidelines for ambulatory BP measurement [25], different criteria were adopted to have BP measurement as reliable as possible. The ABPM sessions were performed during a weekday before the psychological evaluation, and participants were instructed to attend their usual daily activities but to hold their arm stationary during BP readings. Additionally, they filled in a log on the activities carried out during the $\mathrm{BP}$ registration day, and they reported the time of both sleep onset and awakening.

Furthermore, they recorded whether they were out of bed during the night (e.g., to use the bathroom) and the relative awake time. This strategy allows excluding the "out-of-bed" records of the ABPM from the data. Another exclusion criterion for the measurements was the presence of SBP data greater than $240 \mathrm{mmHg}$ or lower than $70 \mathrm{mmHg}$ or DBP data higher than $150 \mathrm{mmHg}$ or lower than $40 \mathrm{mmHg}$. The ABPM dataset included in the analysis should have at least two-thirds of the SBP and DBP measurements during both the daytime and the night-time periods [25]. However, no participants in the study reported invalid data. The ABPM recordings allow calculating the mean arterial pressure $(\mathrm{MAP})$ of wake and sleep through the formula $\mathrm{MAP}=(\mathrm{SBP}+(2 \times \mathrm{DBP})) / 3$, and dipping ratio was assessed by the ratio between sleep MAP and wake MAP [26].

\subsection{Socio-Demographic and Anamnestic Information}

Demographic data (age, gender, years of education), lifestyles (smoking and alcohol consumption), medical, and psychiatric information were collected for each patient by face-to-face interviews.

\subsection{Questionnaires}

20-Item Toronto Alexithymia Scale (TAS-20)

TAS-20 [27,28]: a 20-item self-report questionnaire to evaluate alexithymia. The test assessed three different dimensions of alexithymia: difficulty identifying feelings (DIF), difficulty describing feelings (DDF), and externally oriented thinking (EOT). A 5-point Likert scale classifies the responses ( 1 = strongly disagree, $5=$ strongly agree), and the scores range from 20 to 100 . Higher scores in the three dimensions of TAS-20 and TAS-20 global score identify high alexithymic levels.

\subsection{Procedure}

The study was conducted according to the Declaration of Helsinki and was approved by the Local Ethics Committee (Department of Dynamic and Clinical Psychology— "Sapienza" University of Rome; number: 0001166). After the informed consent was signed, each participant was subjected to office blood pressure assessment; then, weight and height were recorded. Finally, the participants completed the socio-demographic and anamnestic interview and the TAS-20 questionnaire. After this procedure, a cardiologist gave the eventual diagnosis of essential hypertension and classified the dipping status according to the ABPM registration.

\subsection{Data Analyses}

One-way analyses of variance (ANOVAs) were carried out considering the group as the independent variable (non-dippers, dippers, extreme dippers) and the different socio-demographic (age, years of education), physiological (SBP, DBP, MAP day, MAP night, night/day MAP ratio, BMI), and lifestyle (smoking and alcohol consumption) dimensions as dependent variables. 
Finally, ANOVAs on the TAS-20 subscales and TAS-20 global scores were conducted. Planned comparisons were used to analyze significant effects.

The Chi-squared test $\left(\chi^{2}\right)$ was adopted to estimate the differences in the percentage of normotensive, untreated hypertensive, and treated hypertensive participants in the three groups. For all the statistical analyses, the level of significance was accepted at $p \leq 0.05$. Statistical analyses were performed through the Statistica Software v.10.0 (StatSoft.inc., Tulsa, OK, USA).

\section{Results}

Table 1 shows the differences between groups in the main demographic and physiological characteristics.

Table 1. Means $( \pm \mathrm{SD})$ of the main characteristics of the three groups of participants.

\begin{tabular}{|c|c|c|c|c|c|}
\hline & Non-Dippers & Dippers & Extreme Dippers & $F / x^{2}$ & $p$ \\
\hline$n$ (Female/Male) & $70(35 / 35)$ & $70(36 / 34)$ & $70(36 / 34)$ & & \\
\hline Age & $59.99(8.46)$ & $56.10(10.13)$ & $53.69(9.04)$ & 8.29 & 0.001 \\
\hline Years of education & $11.72(3.23)$ & $12.66(3.95)$ & $13.56(4.22)$ & 3.05 & 0.06 \\
\hline Body mass index (BMI) & $26.64(4.99)$ & $25.88(4.28)$ & $26.47(3.69)$ & $<1$ & 0.56 \\
\hline Systolic blood pressure (SBP) & $140.61(22.50)$ & $141.82(18.68)$ & $141.67(18.62)$ & $<1$ & 0.93 \\
\hline Diastolic blood pressure (DBP) & $88.26(12.30)$ & $91.57(12.08)$ & $92.18(10.50)$ & 2.26 & 0.11 \\
\hline Mean arterial pressure day (MAP) & $97.66(10.08)$ & $98.30(9.00)$ & $101.82(8.16)$ & 4.24 & 0.02 \\
\hline Mean arterial pressure night (MAP) & $92.15(9.89)$ & $83.00(7.40)$ & $76.67(6.53)$ & 65.13 & 0.0001 \\
\hline Dipping ratio MAP & $0.95(0.03)$ & $0.85(0.03)$ & $0.76(0.03)$ & 675.4 & 0.0001 \\
\hline Smoking cigarettes (number per day) & $0.30(0.75)$ & $0.51(0.88)$ & $0.32(0.67)$ & 1.50 & 0.23 \\
\hline Alcohol consumption (number of glasses per day) & $0.36(0.48)$ & $0.40(0.52)$ & $0.31(0.53)$ & $<1$ & 0.60 \\
\hline Hypertensive conditions $(n(\%))$ & & & & 16.98 & 0.02 \\
\hline Normotensive & $14(39)$ & $9(25)$ & $13(36)$ & & \\
\hline Hypertensive untreated & $11(16.7)^{\mathrm{a}}$ & $23(34.8)$ & $32(48.5)^{\mathrm{a}}$ & & \\
\hline Hypertensive treated & $45(41.7)^{b}$ & $38(35.2)$ & $25(23.1)^{b}$ & & \\
\hline Alexithymic condition & & & & 19.34 & 0.001 \\
\hline Non-alexithymic & $46(32.1)$ & $55(38.5)$ & $42(29.4)$ & & \\
\hline Moderately alexithymic & $15(32.6)$ & $15(32.6)$ & $16(34.8)$ & & \\
\hline Alexithymic & $9(42.9)^{c}$ & $0(0.0)^{\mathrm{cd}}$ & $12(57.1)^{d}$ & & \\
\hline
\end{tabular}

\subsection{Demographical, Physiological, and Lifestyle Variables}

The ANOVA on age showed significant differences between groups $\left(\mathrm{F}_{2,207}=8.29 ; p=0.001\right.$; $\left.p_{\eta}{ }^{2}=0.07\right)$; non-dippers were older than both dippers $\left(\mathrm{F}_{1,207}=6.19 ; p=0.002\right)$ and extreme dippers $\left(\mathrm{F}_{1,207}=16.27 ; p=0.0001\right)$. No differences were highlighted between dippers and extreme dippers $\left(\mathrm{F}_{1,207}=2.39 ; p=0.13\right)$. Considering years of education $\left(\mathrm{F}_{2,207}=3.05 ; p=0.06\right), \mathrm{BMI}\left(\mathrm{F}_{2,207}=0.59\right.$; $p=0.56)$, systolic blood pressure $\left(\mathrm{F}_{2,207}=0.08 ; p=0.93\right)$, diastolic blood pressure $\left(\mathrm{F}_{2,207}=2.26 ; p=0.11\right)$, cigarette consumption $\left(\mathrm{F}_{2,207}=1.50 ; p=0.23\right)$, and alcohol consumption $\left(\mathrm{F}_{2,207}=0.52 ; p=0.60\right)$, no significant differences were observed among the groups (see Table 1).

The ANOVAs on the two indices of MAP (day and night) showed significant differences.

Considering MAP of day time $\left(\mathrm{F}_{2,207}=4.24 ; p=0.02 ; p_{\eta}{ }^{2}=0.04\right)$ extreme dippers showed higher values than dippers $\left(\mathrm{F}_{1,207}=5.51 ; p=0.02\right)$ and non-dippers $\left(\mathrm{F}_{1,207}=7.23 ; p=0.01\right)$, while dippers and non-dippers were not different $\left(\mathrm{F}_{1,207}=0.12 ; p=0.73\right)$. Considering MAP of night time $\left(\mathrm{F}_{2,207}=65.13\right.$; $\left.p=0.0001 ; p_{\eta}{ }^{2}=0.39\right)$, extreme dippers showed lower values than both dippers $\left(\mathrm{F}_{1,207}=21.53\right.$; $p=0.0001)$ and non-dippers $\left(\mathrm{F}_{1,207}=128.83 ; p=0.0001\right)$; and dippers showed lower values than non-dippers $\left(\mathrm{F}_{1,207}=45.03 ; p=0.0001\right)$ (Figure 1 ; see also Table 1$)$. 


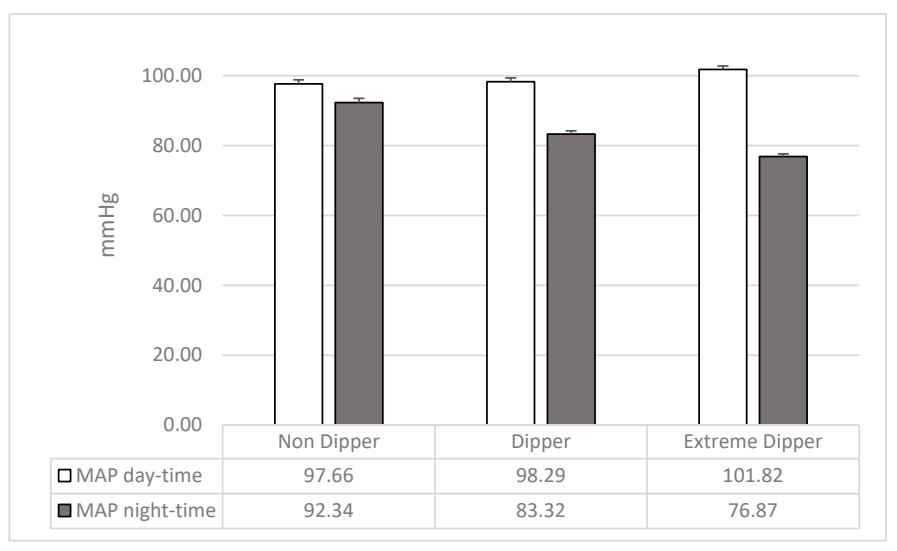

Figure 1. Mean and SD of mean arterial pressure (MAP) of wake and sleep in the three groups of participants.

\subsection{Alexithymia}

Table 2 shows the TAS-20 scores of the three groups.

Table 2. Means $( \pm \mathrm{SD})$ of the TAS-20 scores in the three groups of participants and ANOVAs results.

\begin{tabular}{cccccc}
\hline & Non Dippers & Dippers & Extreme Dippers & F & $p$ \\
\hline DIF & $15.18(6.28)$ & $12.97(4.89)$ & $16.22(6.27)$ & 5.63 & 0.005 \\
DDF & $13.83(4.20)$ & $10.77(3.93)$ & $14.28(4.84)$ & 13.56 & 0.0001 \\
EOT & $19.73(4.95)$ & $18.40(4.71)$ & $18.30(4.87)$ & 1.91 & 0.15 \\
Total score & $48.74(11.43)$ & $42.13(9.67)$ & $48.79(11.86)$ & 8.45 & 0.0003 \\
\hline \multicolumn{7}{l}{ DIF: difficulty identifying feelings; DDF: difficulty describing feelings; EOT: externally oriented thinking. }
\end{tabular}

ANOVAs on the TAS-20 subscales showed significant differences between the groups in the difficulty identifying feelings $\left(\mathrm{F}_{2,207}=5.63 ; p=0.005 ; p_{\eta}{ }^{2}=0.05\right)$ and the difficulty describing feelings $\left(\mathrm{F}_{2,207}=13.56 ; p=0.0001 ; p_{\eta}{ }^{2}=0.12\right)$. Dippers showed lower scores in both the TAS-20 subscales than non-dippers (DIF: $\mathrm{F}_{1,207}=5.02 ; p=0.03$; DDF: $\mathrm{F}_{1,207}=17.41 ; p=0.0001$; see Figure 1 ) and extreme dippers (DIF: $\mathrm{F}_{1,207}=10.79 ; p=0.002 ; \mathrm{DDF}: \mathrm{F}_{1,207}=22.94 ; p=0.0001$; see Figure 1); non-dippers and extreme dippers were not different (DIF: $\mathrm{F}_{1,207}=1.09 ; p=0.30 ; \mathrm{DDF}: \mathrm{F}_{1,207}=0.38 ; p=0.54$; see Figure 2).

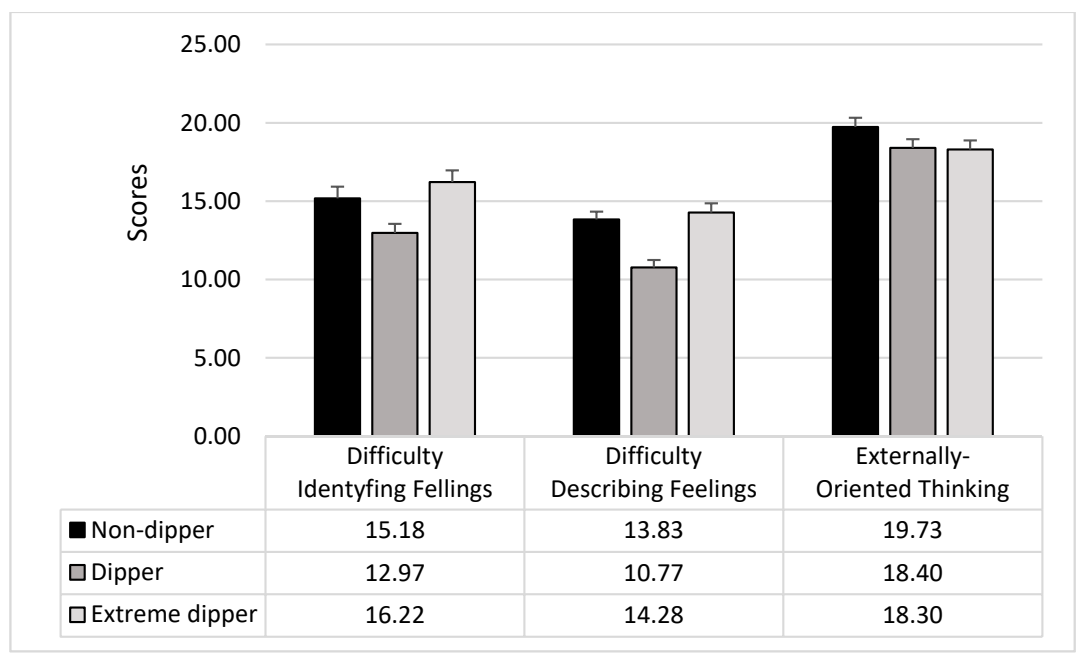

Figure 2. Mean and SD of the TAS-20 subscales in the three groups of participants.

Externally oriented thinking did not result different among the three groups $\left(\mathrm{F}_{2,207}=1.91 ; p=0.15\right)$. 
The ANOVA on TAS-20 global score showed a significant difference among groups $\left(\mathrm{F}_{2,207}=8.45\right.$; $\left.p=0.0003 ; p_{\eta}{ }^{2}=0.08\right)$; dippers showed lower levels of alexithymia than both non-dippers $\left(\mathrm{F}_{1,207}=12.57\right.$; $p=0.0005)$ and extreme dippers $\left(\mathrm{F}_{1,207}=12.77 ; p=0.0005\right)$, while there were no differences between non-dippers and extreme dippers $\left(\mathrm{F}_{2,207}=0.001 ; p=0.98\right)$ (see Figure 3 ).

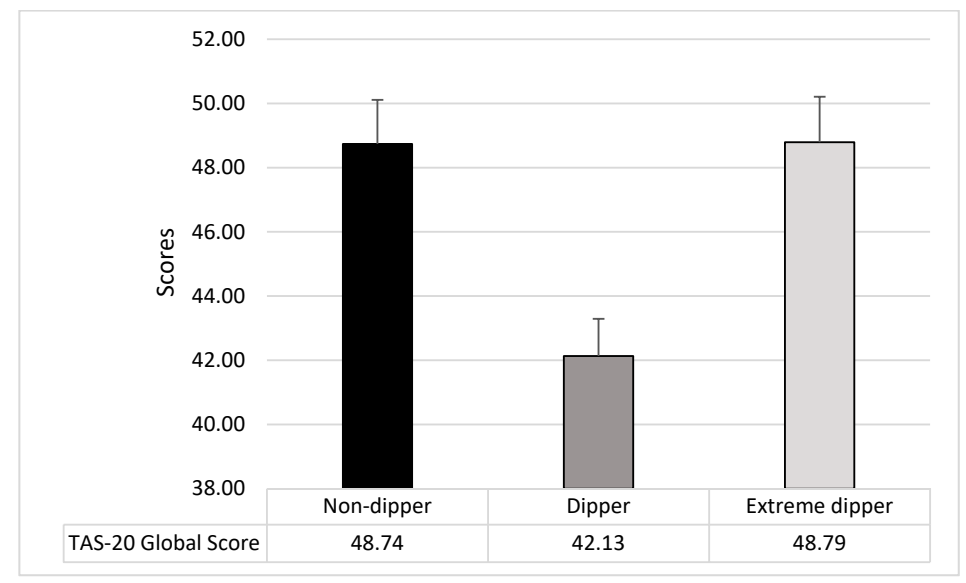

Figure 3. Mean and SD of the TAS-20 Global Score in the three groups of participants.

Since age was significantly different between groups, it was introduced as covariates in the analyses; however, no substantial differences were found. ANOVAs confirmed all significant differences.

\subsection{Alexithymia in Normotensive and Hypertensive Subgroups}

In the hypertensive patients, the ANOVAs showed significant differences in the difficulty identifying feelings $\left(\mathrm{F}_{2,171}=6.28 ; p=0.002 ; p_{\eta}{ }^{2}=0.06\right)$, difficulty describing feelings $\left(\mathrm{F}_{2,171}=12.90\right.$; $\left.p=0.0001 ; p_{\eta}{ }^{2}=0.12\right)$, externally oriented thinking $\left(\mathrm{F}_{2,171}=3.48 ; p=0.03 ; p_{\eta}{ }^{2}=0.04\right)$ and global score $\left(\mathrm{F}_{2,171}=8.90 ; p=0.001 ; p_{\eta}{ }^{2}=0.10\right)$. Planned comparison confirmed that extreme dippers and non-dippers reported higher TAS-20 scores compared to dippers in difficulty identifying feelings (dipper vs non-dipper: $\mathrm{F}_{1,171}=6.88 ; p=0.01$; dipper vs extreme dipper: $\mathrm{F}_{1,171}=11.23 ; p<0.0001$ ), difficulty describing feeling (dipper vs non-dipper: $\mathrm{F}_{1,171}=17.26 ; p=0.0001$; dipper vs extreme dipper: $\mathrm{F}_{1,171}=21.04 ; p=0.0001$ ) and the global score (dipper vs non-dipper: $\mathrm{F}_{1,171}=15.27 ; p=0.001$; dipper vs extreme dipper: $\mathrm{F}_{1,171}=11.08 ; p=0.001$ ),

No differences were reported in normotensive participants $(p>0.05)$.

\section{Discussion}

The dipping phenomenon is a physiological characteristic of the circadian blood pressure rhythm [1]. Alterations in this pattern have important consequences for cardiovascular health. Accordingly, dipping status represents a more reliable predictor of cardiovascular morbidity and mortality than the diurnal BP [29]. Many psychological dimensions are associated with alteration in BP dipping $[17,30]$. For the first time, the present study highlights a relationship of the dipping pattern with another psychological trait, i.e., alexithymia. High levels of alexithymia, expressed by difficulty identifying and describing feelings, were associated with extreme and non-dipping patterns in a sample, including hypertensive and normotensive people.

Previous research evidenced that difficulty identifying and describing feelings characterize people with essential hypertension and adverse cardiovascular outcomes [12-14]. Our results provide additional information to this complex relationship, confirming that individuals with absent or excessive blood pressure dipping present higher emotional dysregulation than individuals with physiological dipping. This result suggests that difficulty in identifying and describing feelings, which represent a typical pattern of problematic processing and managing of emotions and emotional stimuli, could be considered a possible risk factor or a marker of the alteration of circadian BP rhythm. 
In interpreting these outcomes, it must be considered that the autonomic nervous system (ANS) plays a crucial role in this relationship because it appears to be the main mediator of the circadian variation in blood pressure, and it is related to emotional response [31]. In particular, the sympathetic nervous system activity generates the difference between sleep-time and wake-time blood pressure. Moreover, primary autonomic failure and very low sympathetic and parasympathetic activities are associated with a high non-dipping BP incidence. This situation suggests that an altered dipping process is due to the inability to modulate autonomic tone rather than to the failure to inhibit sympathetic activity during sleep [32]. According to this assumption, the increase of cardiovascular risk associated with non-dipping status seems to be due to the difficulty in physiological recovering from the typical demand-driven elevations of blood pressure during the waking hours of the day [33]. Therefore, the non-dipping status appears characterized by a disruption of the circadian autonomic balance [34]. Moreover, an increase in sympathetic nervous system activity results in cognitive and psychological alterations [35-38], also involving emotional regulation ability.

Alexithymia is characterized by somatosensory amplification and hyperarousal, and these features disturb the affective arousal induced by external stimuli [39]. The alteration of the physiological response associated with emotional stimuli, and the fact that some of the areas involved in the elaboration of these stimuli (e.g., amygdala, limbic system) are also involved in the autonomic regulation of circulation responses to stress events [40], would confirm the physiological connection between alexithymic characteristics and the circadian rhythm alteration of blood pressure.

The results concerning externally oriented thinking are in line with this assumption. In our sample, no differences between groups were found in this alexithymic dimension. This result could occur because externally oriented thinking refers more to a cognitive level of emotional process, whereas difficult to identify and describe feelings are closely related and refer to the subjective experience of emotions that are strictly associated with the hyperactivation of the sympathetic nervous system and the consequent hyperarousal [41,42].

When the relationship between the dipping status and alexithymia was separately examined in hypertensive and normotensive participants, a higher emotional dysregulation in extreme dipper and non-dipper individuals was confirmed only in hypertensive patients. This finding suggests that alexithymia may be associated with an alteration of the cardiovascular system in hypertensive participants, which would further compromise hypertension. Moreover, this result could indicate that the well-known relationship between hypertension and alexithymia, e.g., [12-14], is restricted only to hypertensive patients that show an anomalous dipping pattern (i.e., non-dippers and extreme dippers). However, further studies with larger samples are needed to confirm this hypothesis. In fact, the data do not allow any conclusions to be drawn about normotensive people. The small number of normotensive individuals does not allow for an adequate subdivision of participants based on the dipping trend.

The findings of this study are interesting because they were highlighted also controlling a possible influence of demographic (such as gender and years of education), physiological (BMI), and lifestyle (cigarette and alcohol consumption) factors that did not differ among the groups. Only the age was different in the three groups, but the observed results were maintained by introducing this variable as a covariate in the analyses. Moreover, dippers were not different from non-dippers and extreme dippers in the prevalence of normotensive, hypertensive untreated, and hypertensive treated participants. A previous study [12] reported a relationship between alexithymia and uncontrolled hypertension, supporting the hypothesis that higher emotional dysregulation is associated with a high cardiovascular risk. This study reported a non-linear pattern between alexithymia and circadian variation of BP, confirming the role of alexithymia as a possible independent risk factor for cardiovascular disease and a possible psychological marker of BP alterations.

Generally, the importance of controlling the role of the psychological aspects in the circadian variation of $\mathrm{BP}$ and the dipping phenomenon was reinforced by the present findings. Moreover, contrary to previous studies that considered dipping status as a dichotomic or continuous phenomenon, 
our results underlined the importance of a multi-dimensional classification, which considers the different forms of nocturnal blood pressure variation [18].

Although the results are promising, the current study presents some limitations, such as the small sample size. This factor underlines the need to replicate these findings in larger community samples to generalize these results to the general population. Another limit was represented by the use of the ABPM for the assessment of BP. ABPM is characterized by a poor reproducibility of measurements, as highlighted by some authors [43]. However, all precautions were taken to avoid errors, such as using a short bed-time range (00:00-06:00) and using mean arterial pressure (MAP) for the dipping classification [25].

The absence of drug treatment analysis represents another limit because we do not know how antihypertensive treatment could have affected the BP circadian variations. It would be useful to analyze this aspect, which can mediate the relationship between psychological and physiological aspects [12,17]. The last limit to consider is the absence of a group of participants with reverse dipping patterns (i.e., characterized by increased BP during sleep; [18]). This pattern would be associated with high cardiovascular risk and increased mortality [1], and to analyze if and how the psychological variables influenced this pattern appears important.

\section{Conclusions}

Although the knowledge on the association between blood pressure and psychological factors has increased in the last years, confirming the role of different psychological aspect in different types of hypertension $[11,12,17]$, less is known about the influence of psychological characteristics on the circadian rhythm of BP and the dipping phenomenon.

It would be useful to fully understand how blood pressure interacts with other individual traits, such as psychological dimensions, to improve the diagnosis and treatment of hypertension and related disorders.

Our findings suggest that psychological factors may contribute to the description and classification of patients who fail to exhibit adaptive nocturnal blood pressure dipping. It is interesting to note that the relationship between emotional dysregulation, i.e., difficulty identifying and describing feelings, and excessive BP reduction during sleep (extreme dipping) underlines that some psychological aspects could affect the absence of dipping and a maladaptive increase of the dipping phenomenon. These findings suggest that alterations in the circadian pattern of BP can be linked to emotional dysregulation in a non-linear way that should be further examined.

Author Contributions: Conceptualization, M.C., G.F., and G.G.; methodology, M.C., G.F., E.D.P., F.F., G.G., V.L., and A.G.; formal analysis, G.F., M.C., and F.F.; investigation, M.C., G.F., E.D.P., F.F., G.G., V.L., and A.G.; resources, M.C., G.F., E.D.P., F.F., G.G., V.L., and A.G.; data curation, M.C., G.F., E.D.P., F.F., G.G., V.L., and A.G.; writing-original draft preparation, M.C., F.F., A.G., E.D.P., V.L., G.G., and G.F.; writing-review and editing, M.C., G.F., and F.F.; supervision, M.C.; funding acquisition, M.C. and G.F. All authors have read and agreed to the published version of the manuscript.

Funding: This work was supported by the grant no. RM11916B8928A913 from the University of Rome Sapienza and by the grant "Finanziamento di Ateneo per la Ricerca Scientifica: Avvio alla Ricerca-Università "Sapienza" di Roma" no. AR11916B60C7FFAE.

Acknowledgments: We want to thank Alessandro Mingarelli and all those who participated in the data collection.

Conflicts of Interest: The authors declare that the research was conducted in the absence of any commercial or financial relationships that could be construed as a potential conflict of interest.

\section{References}

1. Kario, K.; Schwartz, J.E.; Pickering, T.G. Changes of nocturnal blood pressure dipping status in hypertensives by nighttime dosing of $\alpha$-adrenergic blocker, doxazosin: Results from the HALT Study. Hypertension 2000, 35, 787-794. [CrossRef] [PubMed]

2. Bishop, G.D.; Pek, J.; Ngau, F. Blunted cardiovascular responses to daytime activities as related to reduced nocturnal blood pressure decline. Ann. Behav. Med. 2006, 31, 248-253. [CrossRef] [PubMed] 
3. Fagard, R.H.; Celis, H.; Thijs, L.; Staessen, J.A.; Clement, D.L.; De Buyzere, M.L.; De Bacquer, D.A. Daytime and nighttime blood pressure as predictors of death and cause-specific cardiovascular events in hypertension. Hypertension 2008, 51, 55-61. [CrossRef] [PubMed]

4. De La Sierra, A.; Redon, J.; Banegas, J.R.; Segura, J.; Parati, G.; Gorostidi, M.; Vinyoles, E. Prevalence and factors associated with circadian blood pressure patterns in hypertensive patients. Hypertension 2009, 53, 466-472. [CrossRef] [PubMed]

5. Smolensky, M.H.; Haus, E. Circadian rhythms and clinical medicine with applications to hypertension. Am. J. Hypert. 2001, 14, 280S-290S. [CrossRef]

6. Tadic, M.; Cuspidi, C.; Grassi, G. Heart rate as a predictor of cardiovascular risk. Eur. J. Clin. Investig. 2018, 48, e12892. [CrossRef]

7. Ohkubo, T.; Hozawa, A.; Yamaguchi, J.; Kikuya, M.; Ohmori, K.; Michimata, M.; Tsuji, I. Prognostic significance of the nocturnal decline in blood pressure in individuals with and without high 24-h blood pressure: The Ohasama study. J. Hypertens. 2002, 20, 2183-2189. [CrossRef]

8. Hermida, R.C.; Ayala, D.E.; Mojón, A.; Fernández, J.R. Influence of circadian time of hypertension treatment on cardiovascular risk: Results of the MAPEC study. Chronobiol. Int. 2010, 27, 1629-1651. [CrossRef]

9. Surtees, P.G.; Wainwright, N.W.; Khaw, K.T.; Day, N.E. Functional health status, chronic medical conditions and disorders of mood. Br. J. Psychiatry 2003, 183, 299-303. [CrossRef]

10. Shen, B.J.; Countryman, A.J.; Spiro, A.; Niaura, R. The prospective contribution of hostility characteristics to high fasting glucose levels: The moderating role of marital status. Diabetes Care 2008, 31, 1293-1298. [CrossRef]

11. Casagrande, M.; Boncompagni, I.; Mingarelli, A.; Favieri, F.; Forte, G.; Germanò, R.; Guarino, A. Coping styles in individuals with hypertension of varying severity. Stress Health 2019, 35, 560-568. [CrossRef] [PubMed]

12. Casagrande, M.; Mingarelli, A.; Guarino, A.; Favieri, F.; Boncompagni, I.; Germanò, R.; Forte, G. Alexithymia: A facet of uncontrolled hypertension. Int. J. Psychophysiol. 2019, 146, 180-189. [CrossRef] [PubMed]

13. Todarello, O.; Taylor, G.J.; Parker, J.D.; Fanelli, M. Alexithymia in essential hypertensive and psychiatric outpatients: A comparative study. J. Psychosom. Res. 1995, 39, 987-994. [CrossRef]

14. Jula, A.; Salminen, J.K.; Saarijärvi, S. Alexithymia: A facet of essential hypertension. Hypertension 1999, 33, 1057-1061. [CrossRef] [PubMed]

15. Mezick, E.J.; Matthews, K.A.; Hall, M.; Kamarck, T.W.; Strollo, P.J.; Buysse, D.J.; Reis, S.E. Low life purpose and high hostility are related to an attenuated decline in nocturnal blood pressure. Health Psychol. 2010, 29, 196. [CrossRef] [PubMed]

16. Linden, W.; Klassen, K.; Phillips, M. Can psychological factors account for a lack of nocturnal blood pressure dipping? Ann. Behav. Med. 2008, 36, 253-258. [CrossRef]

17. Casagrande, M.; Favieri, F.; Guarino, A.; Di Pace, E.; Langher, V.; Germanò, G.; Forte, G. The Night Effect of Anger: Relationship with Nocturnal Blood Pressure Dipping. Int. J. Environ. Res. Public Health 2020, 17, 2705. [CrossRef]

18. Kario, K.; Pickering, T.G.; Matsuo, T.; Hoshide, S.; Schwartz, J.E.; Shimada, K. Stroke prognosis and abnormal nocturnal blood pressure falls in older hypertensives. Hypertension 2001, 38, 852-857. [CrossRef]

19. Troxel, W.M.; Buysse, D.J.; Monk, T.H.; Begley, A.; Hall, M. Does social support differentially affect sleep in older adults with versus without insomnia? J. Psychosom. Res. 2010, 69, 459-466. [CrossRef]

20. Tomfohr, L.; Pung, M.A.; Edwards, K.M.; Dimsdale, J.E. Racial differences in sleep architecture: The role of ethnic discrimination. Biol. Psychol. 2012, 89, 34-38. [CrossRef]

21. Fan, L.B.; Blumenthal, J.A.; Hinderliter, A.L.; Sher wood, A. The effect of job strain on nighttime blood pressure dipping among men and women with high blood pressure. Scand. J. Work Environ. Health 2013, 39, 112. [CrossRef] [PubMed]

22. Pierdomenico, S.D.; Pierdomenico, A.M.; Coccina, F.; Lapenna, D.; Porreca, E. Circadian blood pressure changes and cardiovascular risk in elderly-treated hypertensive patients. Hypertens. Res. 2016, 39, 805-811. [CrossRef] [PubMed]

23. Fujiwara, T.; Yano, Y.; Hoshide, S.; Kanegae, H.; Kario, K. Association of cardiovascular outcomes with masked hypertension defined by home blood pressure monitoring in a Japanese general practice population. JAMA Cardiol. 2018, 3, 583-590. [CrossRef] [PubMed] 
24. Mancia, G.; Fagard, R.; Narkiewicz, K.; Redán, J.; Zanchetti, A.; Böhm, M.; Galderisi, M. 2013 Practice guidelines for the management of arterial hypertension of the European Society of Hypertension (ESH) and the European Society of Cardiology (ESC): ESH/ESC Task Force for the Management of Arterial Hypertension. J. Hypertens. 2013, 31, 1925-1938. [CrossRef]

25. O’Brien, E.; Asmar, R.; Beilin, L.; Imai, Y.; Mancia, G.; Mengden, T.; Pickering, T. Practice guidelines of the European Society of Hypertension for clinic, ambulatory and self blood pressure measurement. J. Hypertens. 2005, 23, 697-701. [CrossRef]

26. Loredo, J.S.; Nelesen, R.; Ancoli-Israel, S.; Dimsdale, J.E. Sleep quality and blood pressure dipping in normal adults. Sleep 2004, 27, 1097-1103. [CrossRef]

27. Bagby, R.M.; Parker, J.D.; Taylor, G.J. The twenty-item Toronto Alexithymia Scale-I. Item selection and cross-validation of the factor structure. J. Psychosom. Res. 1994, 38, 23-32. [CrossRef]

28. Bressi, C.; Taylor, G.; Parker, J.; Bressi, S.; Brambilla, V.; Aguglia, E.; Todarello, O. Cross validation of the factor structure of the 20-item Toronto Alexithymia Scale: An Italian multicenter study. J. Psychosom. Res. 1996, 41, 551-559. [CrossRef]

29. Friedman, O.; Logan, A.G. Can nocturnal hypertension predict cardiovascular risk? Integr. Blood Press. Control 2009, 2, 25.

30. Thomas, K.S.; Nelesen, R.A.; Dimsdale, J.E. Relationships between hostility, anger expression, and blood pressure dipping in an ethnically diverse sample. Psychosom. Med. 2004, 66, 298-304.

31. Thayer, J.F.; Hansen, A.L.; Saus-Rose, E.; Johnsen, B.H. Heart rate variability, prefrontal neural function, and cognitive performance: The neurovisceral integration perspective on self-regulation, adaptation, and health. Ann. Behav. Med. 2009, 37, 141-153. [CrossRef] [PubMed]

32. Biaggioni, I. Circadian clocks, autonomic rhythms, and blood pressure dipping. Hypertension 2008, 52, 797-798. [CrossRef] [PubMed]

33. O’Brien, E.; Coats, A.; Owens, P.; Petrie, J.; Padfield, P.L.; Littler, W.A.; Mee, F. Use and interpretation of ambulatory blood pressure monitoring: Recommendations of the British Hypertension Society. BMJ 2000, 320, 1128-1134. [CrossRef] [PubMed]

34. Pickering, T.G.; Kario, K. Nocturnal non-dipping: What does it augur? Curr. Opin. Nephrol. Hypertens. 2001, 10, 611-616. [CrossRef]

35. Forte, G.; Casagrande, M. Heart rate variability and cognitive function: A systematic review. Front. Neurosci. 2019, 13, 710. [CrossRef] [PubMed]

36. Forte, G.; De Pascalis, V.; Favieri, F.; Casagrande, M. Effects of Blood Pressure on Cognitive Performance: A Systematic Review. J. Clin. Med. 2020, 9, 34. [CrossRef]

37. Hypertension, D.A.; Dawood, T.; Lambert, E.A.; Esler, M.D.; Haikerwal, D.; Brenchley, C.; Lambert, G.W. Sympathetic activity in major depressive disorder: Identifying those at increased cardiac risk? J. Hypertens. 2007, 25, 2117-2124.

38. Roth, W.T.; Doberenz, S.; Dietel, A.; Conrad, A.; Mueller, A.; Wollburg, E.; Kim, S. Sympathetic activation in broadly defined generalized anxiety disorder. J. Psychiatr. Res. 2008, 42, 205-212. [CrossRef]

39. Moriguchi, Y.; Komaki, G. Neuroimaging studies of alexithymia: Physical, affective, and social perspectives. BioPsychoSocial Med. 2013, 7, 8. [CrossRef]

40. Kuwaki, T.; Zhang, W. Orexin neurons as arousal-associated modulators of central cardiorespiratory regulation. Respir. Physiol. Neurobiol. 2010, 174, 43-54. [CrossRef]

41. Neumann, S.A.; Sollers, J.J., III; Thayer, J.F.; Waldstein, S.R. Alexithymia predicts attenuated autonomic reactivity, but prolonged recovery to anger recall in young women. Int. J. Psychophysiol. 2004, 53, 183-195. [CrossRef] [PubMed]

42. Goerlich, K.S. Electrophysiology of Alexithymia. In Alexithymia: Advances in Research, Theory, and Clinical Practice; Cambridge University Press: Cambridge, UK, 2018; p. 250.

43. Stergiou, G.S.; Bliziotis, I.A. Home blood pressure monitoring in the diagnosis and treatment of hypertension: A systematic review. Am. J. Hypertens. 2011, 24, 123-134. [CrossRef] [PubMed]

Publisher's Note: MDPI stays neutral with regard to jurisdictional claims in published maps and institutional affiliations. 
(C) 2020 by the authors. Licensee MDPI, Basel, Switzerland. This article is an open access article distributed under the terms and conditions of the Creative Commons Attribution (CC BY) license (http://creativecommons.org/licenses/by/4.0/). 